\title{
Uma vida de histórias escritas a partir de arquivos: entrevista com Mary C. Karasch
}

\author{
A life of stories written inside the archives: interview with Mary C. Karasch \\ Une vie d'histoires écrites à partir des archives: interview avec Mary C. Karasch \\ Una vida de historias escritas en los archivos: entrevista con Mary C. Karasch
}

Ricardo Alexandre Ferreira[1]
Ana Carolina de Carvalho Viotti[2]

Entrevista realizada em agosto de 2015

$\mathrm{M}$ ary C. Karasch (1943-) tornou-se, ao longo de mais de quatro décadas de pesquisas, uma referência entre os estrangeiros que se debruçaram sobre o passado colonial brasileiro. Além do já clássico $A$ vida dos escravos no Rio de Janeiro (1808-1850), ${ }^{3}$ tese de fins dos anos 1970, aumentada e editada em livro nos Estados Unidos em 1987 e por aqui traduzida no ano 2000, a professora, hoje emérita pela Oakland University, é co-organizadora da The encyclopedia of Latin American history (1996) e autora de numerosos artigos e capítulos de livros que transitam por diferentes espaços e temas relativos à então colônia portuguesa nas Américas: de Zumbi dos Palmares às mulheres livres de cor, das doenças e dos cuidados médicos aos índios ladinos, da costa ao centro do Brasil.

A entrevista que o leitor encontrará nas páginas que seguem foi concedida durante sua estada em Franca (SP), onde proferiu a conferência de abertura da XX Semana de História da Universidade Estadual Paulista Júlio de Mesquita Filho (Unesp), "A Escravidão e os Novos Mundos", intitulada "Masters of the Dance: Enslaved Africans in Central Brazil". Naquela conversa, aqui transcrita, a brasilianista tratou de sua trajetória na área de história, teceu algumas aproximações e distanciamentos entre sua experiência de pesquisa e ensino no Brasil e a dinâmica de trabalho e a historiografia norte-americanas; com maior fôlego, falou de sua mais recente e portentosa obra (a ser lançada ainda

Entrevista recebida em 22 de dezembro de 2015 e aprovada para publicação em 17 de fevereiro de 2016.

[1] Professor do Departamento de História da Universidade Estadual Paulista Júlio de Mesquita Filho (Unesp) - Franca (SP) - Brasil.

E-mail: ricalexe@franca.unesp.br

[2] Doutoranda em História da Universidade Estadual Paulista Júlio de Mesquita Filho (Unesp) - Franca (SP) - Brasil.

E-mail: anacarolina@franca.unesp.br

[3] Ganhador do prêmio Albert J. Beveridge, da American Historical Association, anualmente concedido ao melhor livro em inglês sobre a

história dos Estados Unidos, da América Latina e do Canadá, de 1492 ao presente. 
em 2016), não se furtou de ponderar sobre a multifacetada relação dos historiadores com ativistas sociais e lançou luz sobre um aspecto que salta aos olhos na leitura de qualquer um de seus textos: o contato intenso - e para ela incontornável — com os arquivos.

1. A senhora poderia começar nos falando um pouco sobre o início de sua trajetória como historiadora? O que a levou a se interessar pela área de história e a dedicar-se a essa carreira?

Já faz muito, muito tempo... Eu sempre amei história, desde quando estava na escola secundária. Costumava ler livros de história apenas por diversão. Quando fui para o college, tive bons professores dessa disciplina e resolvi continuar com ela nos meus undergrad studies - em história da África e em história do Brasil.

2. E por que a história do Brasil, especificamente? Quais temas da história brasileira atraíram sua atenção nesse primeiro momento?

Estudei português com brasileiros, porque naquele tempo era preciso cursar certo número de línguas estrangeiras - e eu já tinha cursado francês -, então escolhi o português. Então, em parte esse interesse pelo Brasil é devedor da experiência com a língua. Lembro-me de ler Gilberto Freyre e de me interessar muito pelo que ele apresentava, e de ter contato com Joseph Miller - que hoje é um reconhecido africanista - e que discordava completamente do que Freyre argumentava. Era uma discussão muito interessante e que chamou minha atenção. Daí em diante, passei a procurar e a estudar cada vez mais livros que tratavam da história do Brasil. Thomas Skidmore foi outro autor bastante relevante para minhas reflexões nesse início.

3. Os estudos sobre a escravidão africana nos Estados Unidos são bastante desenvolvidos e carregam diversas e calorosas polêmicas interpretativas, muito instigantes. Embora a senhora já tenha citado Gilberto Freyre, como se deu seu interesse em estudar o cativeiro de africanos na América portuguesa?

Muito se deve a eu também estar estudando, nesse período, a história da África. Minha dissertação de mestrado tratava do tráfico ilegal entre Angola e a cidade do Rio de Janeiro, e desenvolvendo esse estudo pude perceber que Gilberto Freyre estava completamente errado em sua tese, em termos das ligações entre Angola e Brasil. Ele deu preferência, em seus estudos, às gentes que vieram da África oeste, mas me parece que ele não conhecia muito sobre o povo angolano. Eu, por minha vez, passei a me debruçar sobre os arquivos cariocas para compreender as condições de transporte, chegada e estabelecimento dos escravos nessa cidade, pautada por indícios mais precisos que os aventados por ele, ou, em poucas palavras, resolvi voltar meus esforços para entender um pouco mais sobre a vida dos escravos no Rio de Janeiro. 
Quando cheguei [ao Rio de Janeiro] em 1968, os brasileiros me falavam que era impossível estudar o cotidiano dos escravos africanos porque tudo havia sido queimado [por ordem de Rui Barbosa] na grande queima de 1888 e em um incêndio que ocorrera no arquivo da Irmandade de Nossa Senhora do Rosário do Rio de Janeiro. Por causa disso, os intelectuais sempre afirmavam que não era possível trabalhar esse tema.

4. É muito interessante para as novas gerações de historiadores o fato de a senhora e outros pesquisadores norte-americanos - como Charles Boxer, Stuart B. Schwartz, Stanley Julian Stein, John Russell-Wood, entre outros se deslocarem aos arquivos brasileiros e encontrarem uma situação diversa daquela pintada pelos pesquisadores daqui, mesmo com todas as dificuldades e prejuízos decorrentes dessas grandes perdas de documentos. É curioso ainda lembrar que outro historiador norte-americano, há anos radicado no Brasil, o professor Robert Slenes, publicou no início dos anos 1980 um instigante artigo, intitulado "O que Rui Barbosa não queimou". Como a senhora analisa esse protagonismo de pesquisadores estrangeiros que acabou por abrir um conjunto amplo de novas perspectivas sobre o estudo do cotidiano dos escravizados no Brasil?

Lembro-me que, quando comecei o livro sobre os escravos no Rio de Janeiro, indo aos arquivos, encontrava só pessoas mais velhas, homens aposentados com cabelos brancos e os estrangeiros. Era esse o cenário da pesquisa em arquivos. Os alunos não estavam lá por razões diversas e que eu não compreendia à época, pois a formação nos Estados Unidos nos indicava a necessidade de tratar dessas fontes primárias, desses documentos. Acredito que a falta de experiência e de interesse nos arquivos foi a grande responsável pela reprodução uníssona, durante muito tempo, dessa ideia de que o fogo acabou com todo e qualquer vestígio desse passado tão interessante.

5. Nesse período referido pela senhora, os anos finais da década de 1960, os programas de pós-graduação brasileiros estavam bastante circunscritos ao Rio de Janeiro e a São Paulo. Menos de uma década depois, porém, antes ainda do aumento e da disseminação de centros de pesquisa, a senhora ministrou aulas em Brasília, na Universidade de Brasília (UnB). Poderia nos contar um pouco sobre sua experiência nessa universidade e sobre sua percepção do trabalho nos arquivos?

A experiência em Brasília foi muito interessante para mim, porque eu podia andar pela cidade, encontrando a população sertaneja, tendo mais contato com os costumes do sertão do país e com os pequenos e tão ricos arquivos locais. No Departamento de História, por sua vez, havia pesquisadores que estavam desenvolvendo bons estudos sobre o Brasil; creio que estudos mais sérios e de maior fôlego envolvendo a documentação de arquivo passaram a tomar corpo nesse período. 
Quando iniciei minha investigação em Goiânia, já entre os anos 1980 e 1990, eu era, muitas vezes, a única pessoa trabalhando no arquivo. Houve, ainda assim, um período em que os alunos se voltaram aos arquivos, mas em conversa recente com uma de minhas ex-alunas em Goiás ela me informou que os próprios professores não têm estimulado ou enviado os discentes para a pesquisa nesses locais, o que a deixou bastante preocupada. A mim também. Parece ter havido um refluxo - uma ida aos arquivos e, agora, uma retração desse tipo de trabalho, o que é preocupante.

6. Ainda sobre os anos 1960-1970, um período particularmente conturbado na história brasileira, a senhora encontrou, como estrangeira, alguma dificuldade de acesso à documentação que lhe interessava?

Em geral, não tive problemas. Mas me lembro de não conseguir entrar na Cúria Metropolitana do Rio de Janeiro em 1968, 1969, pois ela foi fechada a todos. Ninguém podia entrar. Tive acesso à Santa Casa de Misericórdia, que tem tantos dados a respeito das condições de saúde dos escravos e das mortes deles. Isso foi muito valioso - e parte importante do livro foi feita a partir dessa documentação. Os arquivos do Itamaraty também foram importantes, e tive acesso a eles sem qualquer restrição ou problema: lá, consegui as listas dos africanos emancipados. Com o Arquivo Nacional, a Biblioteca Nacional e o Instituto Histórico e Geográfico Brasileiro, tudo foi mais fácil.

7. Ainda hoje, muitas vezes os pesquisadores acabam encontrando entraves burocráticos à execução de seus trabalhos nos arquivos, por aberturas e fechamentos dos acervos sem um aviso prévio ou atrelados a determinações exclusivas de seus mantenedores. A Santa Casa de Misericórdia do Rio é um exemplo recente.

Novamente? Que pena! Não é a primeira vez que tenho notícia disso. Em outra ocasião, soube que esse rico acervo estava, mais uma vez, fechado ao público... Felizmente, pude consultá-lo para minha tese.

8. Esse tipo de barreira é encontrado também por seus alunos nos Estados Unidos?

De forma alguma. Eles não encontram qualquer problema para esse trabalho. Acredito que tenhamos bem menos entraves burocráticos nesse sentido. $\mathrm{O}$ acesso a nossos arquivos e bibliotecas me parece muito menos "político" ou burocrático. Nosso problema, muitas vezes, é conseguir um financiamento ou uma bolsa para o aluno se deslocar, por exemplo, até a Biblioteca do Congresso ou o Arquivo Nacional em Washington, D.C. São questões mais voltadas à falta de dinheiro para as viagens e permanência em outras cidades do que barreiras dos coordenadores ou arquivistas, como muitas vezes os brasileiros relatam enfrentar. 
Outra coisa, ainda sobre o acesso aos repositórios brasileiros. A Cúria Metropolitana: eu estava muito feliz em finalmente ter acesso e fazer pesquisas em seus acervos, quando procurava documentação sobre a capitania de Goiás, uma vez que Goiás esteve sob os auspícios do bispo do Rio. Eu acreditava que deveria haver correspondências de muito interesse entre o bispo do Rio de Janeiro e certo padre que era frequentemente citado em outros documentos. Mas não localizei nada. No final, encontrei documentos muito interessantes sobre o Mato Grosso, as investigações de bruxaria e concubinato, e muito pouco sobre Goiás - e que apresento em meu livro que será em breve lançado. No final, depois de tanto tempo desejando consultar esses arquivos da Cúria, foi um prazer ver essa documentação. E ainda acabei recebendo um tour pelo arquivo! O arquivista me conhecia, conhecia meu trabalho e queria me mostrar toda a riqueza do acervo que ele administrava.

9. Aproveitando que a senhora mencionou sua pesquisa recente, poderia nos falar sobre o livro que será lançado em 2016 (em inglês)? Tivemos o privilégio de ouvir um pouco sobre o trabalho na XX Semana de História da Unesp/campus Franca e gostaríamos de conhecer um pouco mais dessa exaustiva pesquisa sobre a capitania de Goiás.

Essa obra tratará de muitos assuntos, não somente da escravidão - o tema que apresentei no evento. A escravidão, vale ressaltar, é uma das diversas linhas que procuro abordar no livro. Nele, trato do período que vai de 1775 a 1835, com algumas referências anteriores sobre as bandeiras e, algumas vezes, informações sobre o que se passou depois. Creio ser interessante falar um pouco mais do percurso do livro como um todo, dividido em 10 capítulos.

O primeiro capítulo trata um pouco da geografia e das doenças da região. É um estudo para mostrar como foi possível o estabelecimento de pessoas e atividades em Vila Boa de Goiás, como se deram as viagens, por exemplo, e como as longas distâncias para lá chegar e se permanecer foram vencidas, notadamente pelas gentes de São Paulo e seus escravos. O segundo versa sobre os grupos indígenas, quem estava lutando contra a invasão das terras sertanejas e um pouco sobre o que aconteceu com esses índios que acabaram sendo escravizados e utilizados como mão de obra em Goiás. Falo também do comércio (ou tráfico) desses indígenas para São Paulo e outras capitanias. No terceiro capítulo, abordo as grandes bandeiras para Goiás, inseridas na escravização dos índios - pois, como vocês sabem, Goiás foi um dos grandes polos de escravização dos nativos para a empresa das bandeiras - e, nesse sentido, há uma vasta documentação sobre essa penetração pela capitania de Goiás, tanto de bandeiras do Mato Grosso quanto de São Paulo, Minas Gerais e também do Maranhão. Foi impressionante ver quantas bandeiras estavam trabalhando nessa região. No quarto capítulo, então, volto-me para as guerras resultantes desse tenso contato entre indígenas e bandeirantes. 
Já no quinto capítulo, desloco meus esforços para a apresentação e compreensão do sistema imperial, na tentativa dos portugueses de estabelecer a governança da região, em termos de estrutura administrativa e também de negócios. Falo dos mercadores do mar e de suas relações comerciais com a Vila Boa de Goiás, da troca de ferramentas, tecidos e outras coisas por ouro. Outro aspecto interessante é sobre o câmbio de sal pelo ouro, em decorrência da notável carestia de sal na citada vila e em outras pequenas aldeias de mineração. Isso corrobora, como temos conversado, o processo de interiorização do Brasil no período colonial. Vejam que o sal marinho de Belém estava sendo negociado nas áreas de mineração goianas através do rio Tocantins, e não somente oriundo de áreas ao sudeste. As estradas do sertão, desde Salvador até Cachoeira e pequenas aldeias, como Natividade, no norte, por exemplo, foram essenciais para o sucesso desse abastecimento. Em linhas gerais, portanto, abordo o governo imperial, os negócios controlados pelos portugueses e o grande movimento de ouro e outros produtos na capitania nesse tópico.

\section{Quando cheguei (ao Rio de Janeiro) em 1968, os \\ brasileiros me falavam que era impossivel estudar o cotidiano dos escravos africanos porque tudo havia sido queimado}

Goiás, como aprendi, era uma das capitanias mais ricas do Brasil no fim do século XVIII, a quinta em ordem de importância, mais ou menos, mas em razão, principalmente, do gado. Nunca pensei que encontraria tantas informações sobre o envio de receitas (income) para Portugal, sobretudo o nível de importância que pude detectar. Minas Gerais, obviamente, estava muito acima quando se pensa em produtividade de ouro, isso está fora de questão. Penso que conhecemos mais a respeito do ouro em Minas Gerais; já em relação a Goiás e Tocantins, muito do ouro saiu em forma de contrabando - portanto, não sabemos ao certo sobre o volume da produção dessa região. Quando fui a Natividade [Tocantins] uma vez, comprei este cordão de ouro que estou usando, pois lá ainda há minas de ouro ativas, ainda há grande empresa de mineração em Cavalcante [Goiás]. Digo isso para frisar que não sabemos o quanto de ouro pode ter saído de lá no período colonial. Vejo com frequência na documentação os portugueses se queixando do contrabando, e todo o sistema de impostos criado naquela época foi uma tentativa de barrar esse comércio ilegal de ouro que rumava em todas as direções pelo Brasil.

Então, retomemos o livro. No sexto capítulo, trato das elites de Goiás, dos homens que eram proprietários de mais de 100 escravos, proprietários de 
minas e também de engenhos. No século XVIII, há ocorrências de engenhos com mais de 100 escravos, como havia na costa do Brasil: essa foi uma das surpresas que encontrei.

10. Sobre essa matéria, o professor Stuart Schwartz argumenta em alguns dos textos que escreveu sobre a Bahia que haveria poucos engenhos com mais de 100 escravos, porque médios e pequenos proprietários se tornavam prestadores de serviços para esses engenhos maiores. A senhora, no entanto, encontrou registros de propriedades que detinham uma centena de escravos.

Sim. Mas vale destacar que não eram extremamente frequentes ou muito grandes. Minha ideia é que as pessoas iam, primeiramente, para fazer a extração e mineração do ouro, pouco preocupadas com a fixação. Sei que, a princípio, os senhores alimentavam seus escravos apenas com pipocas e guariroba, ocasionando má nutrição geral dos cativos nesse período inicial. Depois, passaram a empregar a mão de obra escrava também na agricultura, especialmente na produção de milho e mandioca, e geralmente eram as mulheres as responsáveis pelo cuidado das roças de comida. Houve também fazendas de gado - os suínos não são muito encontrados nesse início da ocupação - e a criação de cavalos. O gado se espalhou facilmente, vindo em busca de água pelo rio Tocantins a partir da Bahia: muitas vezes, as pessoas apenas "pegavam" o gado alheio para também alimentar os escravos. Estou utilizando as sesmarias para determinar que efetivamente houve esse processo de agricultura com criação de gado ao lado da mineração.

O capítulo seguinte da obra, o sétimo, trata propriamente da escravidão africana - como esses escravos foram usados na mineração e na agricultura. Aqui, me vali do modo "tradicional" de estudar a escravidão, quer dizer, com muitas estatísticas. Faço ainda algumas indicações sobre o modo de vida desses cativos e, como vocês puderam ver na conferência de abertura do evento, falo um pouco dos costumes e da religiosidade desses homens escravizados. Adiante, no oitavo capítulo, volto-me para a Igreja em Goiás - ou, posso dizer, da falta da Igreja em Goiás -, porque, em termos de estrutura eclesiástica, ou do número de igrejas construídas no período, quando havia muito ouro, o número de padres trabalhando em Goiás era alto, mas com o declínio da mineração vejo que a atuação da Igreja se torna mais fraca. Há uma porção de livros que tratam das igrejas lá construídas, aliás. Nessa parte do livro, abordo outros assuntos mais voltados para as elites católicas da região, e depois disso me volto para as irmandades irmandades dos brancos, dos pardos, dos pretos —, especialmente para a irmandade de Nossa Senhora do Rosário. Esse capítulo é uma tentativa de mostrar o lado eclesiástico e também o lado popular das manifestações religiosas, pois em Goiás, como vocês devem saber, há uma tradição voltada à religiosidade, às romarias, às procissões e todos esses elementos, o que 
nos faz querer saber um pouco mais como essas manifestações se formaram. Tento tratar disso, incluindo todos os grupos mencionados: brancos, pardos e negros.

No capítulo seguinte, trato das questões de gênero, das relações e dos papéis de homens e mulheres. Nessa parte, utilizei muito a documentação que falava da Cúria do Rio de Janeiro. Os documentos da Cúria em Goiânia agora estão arquivados, separados dos demais arquivos da Igreja, bem guardados e conservados, e podem ser consultados pelos pesquisadores. É ótimo. Uma das grandes preocupações dos padres foi o concubinato homens brancos com mulheres africanas e indígenas, com mulheres de todas as cores - e a prostituição; isso aparece no nono capítulo. Outro comportamento que parece ter atraído a atenção era a constante relação entre padres e mulheres na capitania: eles não eram muito celibatários.

11. Essa documentação da Cúria vem sublinhar o comportamento dado como inadequado por parte dos padres que tanto aparece nas correspondências presentes no Arquivo Histórico Ultramarino?

Sim, com certeza. E é interessante que, quando estudei os registros de óbitos na pequena cidade de Natividade, por exemplo, o padre que fazia as listas das mortes parecia tão carinhoso e atento à situação dos escravos... Foi ele quem notou os maus-tratos e denunciou um senhor que matou cruelmente um de seus cativos - posso dizer que foi um dos primeiros a registrar algo assim na capitania, uma pessoa que estava tentando ajudar o povo contra os maus senhores. Ele estava sempre protestando contra atos bárbaros e contra os senhores que não mandavam os escravos para serem sepultados no campo santo. Mais tarde, com o avanço de minhas pesquisas, percebi que ele não era adepto do celibato: teve uma mulher, acho que seis crianças (não me recordo exatamente o número) e era pardo, homem de cor. Pela confluência desses fatores, acho muito interessante pontuar aqui essa breve história. Pois bem, nesse capítulo trato desses assuntos.

Finalmente, o livro termina com a última geração da gente livre de cor da capitania. No percurso da obra, procuro mostrar que começamos com todos esses grupos submetidos à escravidão, como os grupos indígenas - e que perdurou ao longo do tempo, já que há registros da contínua escravização de índios e de seu envio para Belém até o início do século XIX - e os africanos, mas que já ao final do período em que me debruço há um recenseamento que indica que a maioria da população de Goiás era de gente livre e de cor. Os brancos estavam saindo da capitania, mas a gente de cor ainda estava lá, trabalhando especialmente na agricultura, com alguma atividade na mineração - quadro muito semelhante ao encontrado em Minas Gerais. 
12. Em sua narrativa sobre a construção do livro, chama a atenção a diversidade de assuntos tratados e que, acreditamos, seja fruto do estudo em uma ampla gama de documentos e ao longo de bastante tempo. Como foi o processo de formatação da ideia da obra, que tipos documentais a que senhora precisou recorrer para responder às questões postas e, ainda, há quantos anos tem trabalhado nesse projeto?

Goiás era uma das capitanias mais ricas do Brasil no fim do século XVIII, a quinta em ordem de importância, mais ou menos, mas em razão, principalmente, do gado

Na verdade, não queria falar sobre o tempo, pois já faz muito... Quando fui para Goiânia, à época em que lecionava na UnB, encontrei-me com frei Simão, um padre que levou inúmeros documentos para Goiás, e vi o que não pude consultar na cidade do Rio de Janeiro. Esse foi o início. Entretanto, não podia me dedicar ao projeto sobre Goiás, pois ainda estava trabalhando em A vida dos escravos no Rio de Janeiro, publicado em 1987 [em inglês]. Assim que esse livro saiu, comecei a trabalhar, com uma bolsa de pesquisa, nesse novo projeto. Iniciei as pesquisas em Brasília - eu tinha uma ex-aluna que era bibliotecária na Biblioteca do Senado, onde passei a estudar os relatórios dos governos de Goiás e outros documentos.

De Brasília fui para Goiânia, e foi muito engraçado o que aconteceu no início. Não pensei em consultar nas universidades se era fácil localizar os arquivos de lá. Pensava: "só preciso perguntar para alguém na rua 'onde está o arquivo?'; todos devem saber". Ninguém sabia. Acabei indo de um lugar para o outro sem encontrar, até que finalmente uma pessoa me disse para perguntar no Ministério da Educação, que certamente alguém lá me explicaria. Fui até lá e finalmente encontrei o arquivo! Nesse período da pesquisa, o arquivo estava localizado em um lugar pequeno, e o padre Luís, um jesuíta, estava organizando os documentos. E eu estava lá, de caixa em caixa, olhando e olhando, quando comecei a encontrar coisas de interesse. Também na cidade de Goiás, no Museu das Bandeiras, pude ter contato com as riquezas que ele guardava. No meu tempo de pesquisa, não pude ver tudo - e ainda há muitas coisas em embalagens não catalogadas. É uma tragédia que isso ainda não esteja organizado, na verdade. Já o arquivo de frei Simão estava localizado em uma biblioteca, e eu consultei os documentos nesse espaço, e foi muito fácil, nunca precisei requerer permissão ou algo do tipo. Esse foi o início, em 1986-1987. 
13. Nesse trabalho com os arquivos — levantamento de dados, transcrição de documentos -, a senhora contava com auxílio de uma equipe?

Não, sempre trabalhei sozinha. E por uma razão muito simples: não havia financiamento para isso. O sistema nos Estados Unidos é composto em sua maior parte por pesquisadores solitários, embora eu adore a ideia de trabalho em equipe: é excelente para o professor ter esse apoio, mas é mais interessante ainda para os alunos, que aprendem o trabalho de pesquisa empiricamente. Quando eu estava dando aulas na Universidade Federal de Goiás (UFG), já na década de 1990, mandei os alunos para os arquivos. Eles pesquisaram e coletaram uma série de informações, mas nunca tive algo mais organizado em termos de equipe, algo fixo.

14. A relação próxima da senhora com os arquivos fica evidente em suas obras e em sua fala. Sabemos ainda que a senhora acompanha de perto a produção bibliográfica, e exatamente no período entre o lançamento de Slave life in Rio de Janeiro e a edição da obra em português, no ano 2000, a historiografia brasileira tratou de muitas polêmicas - era predominante uma visão devedora das décadas de 1960 e 1970, cujo enfoque na violência tentava combater a imagem de que no Brasil a escravidão fora mais "branda". Depois do centenário da Abolição, em 1988, o que se viu foi um diálogo mais intenso dos historiadores brasileiros com estudos culturais ingleses e norte-americanos culminando em trabalhos que, para alguns especialistas, visaram de maneira um pouco excessiva à chamada "agência ou autonomia escrava." Como a senhora avaliou esse movimento?

Lidamos sempre com essa contradição entre violência e autonomia. Acredito que muitos escravos conseguiram ter essa autonomia, mas dependendo muito de seu trabalho, por exemplo, na mineração, os escravos que andavam como faisqueiros; eles estavam sozinhos na busca do ouro e, quando localizavam minas muito ricas, acabavam comprando sua própria liberdade. Na capitania de Goiás, veem-se muitos livres e libertos, notadamente por essa possibilidade, essa agência, para comprar a alforria. De outro lado, no entanto, quando se tinham essas grandes empresas mineradoras de escravos, especialmente em minas subterrâneas e galerias, sua atuação era muito reduzida, pois estavam bem controlados. Creio, assim, que as duas coisas - a repressão violenta e a autonomia - puderam existir ao mesmo tempo. Não podemos esquecer que o sistema escravista fora pautado pelo controle muitas vezes cruel.

15. Embora suas pesquisas recentes tenham se voltado para Goiás, falar de A vida dos escravos no Rio de Janeiro, sua obra de maior circulação no Brasil e referência na historiografia sobre a escravidão, é quase incontornável —ou, por que não, irresistível. Gostaríamos que a senhora comentasse um aspecto particular dessa obra: a utilização das narrativas e crônicas de viagem 
como fonte para a história, documentos que por aqui são vistos com certa desconfiança por muitos historiadores.

Quando cheguei ao Rio para as primeiras pesquisas, fui diretamente para a Biblioteca Nacional e encontrei muitos desses viajantes. Ao lê-los, meu entendimento sobre o cotidiano carioca foi extremamente alargado, e, acreditem, sempre tive em mente os problemas de utilizar a literatura de viagem. Já li tantas coisas malfeitas utilizando os viajantes estrangeiros, e o tipo de coisa que eu mais vejo é a utilização desses relatos como fonte única do trabalho, simplesmente porque é mais fácil: basta ir a uma biblioteca e você encontrará livros e mais livros, e tem-se a impressão de que tudo que é necessário para refletir sobre os escravos está lá. Acredito, no entanto, que isso é só o início do trabalho. Não só em A vida dos escravos, mas também depois, utilizei-me das narrativas de viagem.

\section{As duas coisas - a repressão violenta e a autonomia \\ - puderam existir ao mesmo tempo. Não podemos esquecer que o sistema escravista fora pautado pelo controle muitas vezes cruel}

Para a capitania de Goiás, tenho a sorte de ter alguns viajantes estrangeiros que considero excelentes, como Johann Pohl, que circulou pela capitania no início do século XIX, que era cientista - anotou com os "olhos" de cientista - e que observou, por exemplo, o povo xavante; tenho imensa confiança em seu relato. Também é ele quem fala das manifestações religiosas afro-brasileiras, dos músicos que entravam cantando e tocando instrumentos africanos nas igrejas, e, embora haja poucas descrições sobre isso, pude encontrar documentos na Cúria onde os padres se queixavam dessas danças, corroborando seu relatório. Outro viajante, mais famoso, é Saint-Hillaire, que deixou relatos muito interessantes e em quem também confio. Temos, ainda, Raimundo José da Cunha Mattos, português que serviu em Angola - e, portanto, que teve toda a experiência em Angola antes de vir para o Brasil - e que pode entender tantas coisas em Goiás por causa de seu background na África. Suas informações são muito ricas. Para interpretar esses e outros relatos, é necessário considerar também o que se vê em outras fontes.

Pude ler tantos livros e tantas referências de pessoas que foram a Goiás apenas para caçar, pessoas que não sabiam de muitas coisas e que não foram a essa região para observar e falar do povo, do cotidiano. Como com qualquer fonte, há relatos de boa qualidade e outros que vieram da pena de quem mal podia escrever. 
16. Considerar a formação pretérita dos viajantes é, então, parte de sua metodologia para tratar essa documentação?

Com certeza. A formação anterior, as experiências narradas e sua origem. Para o caso de Goiás, tenho um português, um francês e Pohl, que chegou à missão austríaca. E gostaria de contar um pouco mais sobre ele. Há notícias de que ele encontrou certa vez com um bandeirante em Goiás, e que esse bandeirante lhe deu uma pedra, utilizada como munição em armas naquela época. Sabia que ele havia levado essa pedra consigo para a Europa, pois escreveu sobre isso. Fui então para Viena, ao Museu Etnográfico - e infelizmente para nós, que gostamos desse tipo de vestígio afro, não havia absolutamente nada lá. Procurava um tambor, ao menos uma pequena estátua, mas não, nada: só resquícios sobre índios.

17. Em sua fala, então, é possível depreender que o uso de documentos diversos é possível e desejável, desde que com uma posição crítica, fazendo-a lançar mão de um vasto leque interpretativo.

Sim. Acredito que é preciso considerar todas as possibilidades, porque, no final das contas, a história é complicada. Tenho uma teoria, sim, mas a teoria, muitas vezes, só trata de uma pequena parte da experiência. Creio ser importante conversas com a teoria, mas é preciso ser aberto. É por isso que insisto que é preciso entrar nos arquivos, é preciso prestar atenção no que o documento está falando. Quando passei a estudar o Rio e procedi à leitura dos documentos policiais, tinha a ideia prévia de que a polícia naquele período deveria ser horrível, uma relação estritamente coercitiva com os escravos, mas acabei encontrando relatos de pessoas que estavam, antes, preocupadas com a crueldade cometida contra os escravos. Indo ao documento, então, vê-se que é tudo mais complexo do que essa primeira visão dualista.

18. As bases de dados sobre o tráfico de escravos, notadamente a que é fruto do projeto Slave Voyages, também são consideradas em seus trabalhos?

O tráfico também me interessa bastante, especialmente o interno. Já utilizei muitas vezes essa base e a considero excelente. Recorri a ela, por exemplo, quando precisava saber mais sobre os nomes que tenho encontrado nos documentos de arquivo; ou para entender como as gentes africanas chegaram à capitania [de Goiás]. Agora, sei que o Maranhão era um porto de entrada, Belém - pelos rios do norte até as aldeias de mineração - , também Salvador. Vejo que povos chegados a esses portos são frequentes na capitania, como os iorubás - vendidos em Salvador e presentes aos montes em Vila Boa de Goiás. Não posso deixar de mencionar o porto do Rio, que conheço bem, e seu volume na Vila Boa de Goiás. Portanto, é interessante conjugar os dados presentes nessa base com outros dados retirados dos arquivos. 
Em conversa recente com outro pesquisador, tive notícia de que muito do que se sabe sobre o tráfico em Cuba será revisto, mesmo na Slave Voyages Database, porque muitos dos arquivos pequenos nunca foram consultados. Acredito que o mesmo ocorrerá no Brasil: muitos pequenos portos, em muitos pequenos lugares, não foram contabilizados. Arquivos pequenos ainda conservam documentos de entrada de escravos não consultados, e isso pode mudar o número conhecido de africanos aqui aportados.

19. Uma última questão para encerramos esta entrevista: no Brasil, muitas vezes encontramos certo dogmatismo nas posições assumidas pela historiografia e pelo movimento negro na seleção de fontes que devem ou não ser utilizadas, mesmo no debate sobre o peso da violência como um dado para se pensar a relação senhor-escravo. Muitas vezes, se a história narrada não serve a determinada luta, não é aceita ou bem vista. Mas isso não é exclusividade de nossa produção. A senhora tem alguma consideração a fazer sobre a relação entre a historiografia da escravidão e os ativistas da causa negra?

Sim, isso também acontece muito e é um grande problema nos Estados Unidos. Nós, historiadores, temos o compromisso de mostrar como as coisas eram no passado, gostando dele ou não. Muitos afro-americanos não aceitam as conclusões a que os historiadores chegam, deslegitimam o que eles estão localizando. É um grande problema. Penso, no entanto, que os historiadores devem ser fiéis ao que encontram nos documentos para tentar entender o passado; temos uma narrativa a fazer.

Muitas vezes, a população afrodescendente tenta enfatizar apenas suas tradições, mas penso que deveriam reunir outras informações para suas comunidades para ter uma melhor visão do que se passou. Sublinho que acredito ser muito importante ouvir o que as pessoas têm a dizer sobre sua própria história, entender sua perspectiva, mas o passado expresso nos documentos não pode ser descartado, e o lado político, sempre presente, deve ser neutralizado nas pesquisas e conclusões.

Nos Estados Unidos, por exemplo, um dos grandes assuntos de pesquisa pelos afro-americanos são estudos sobre família, incluindo estudos genéticos para saber de onde as pessoas vinham. Estão sendo descobertas e reunidas as tradições da família - e me recordo agora de Louisiana - , como o caso de um antepassado francês, com amante africana, também com mistura com índios... quer dizer, uma família pode ter todas essas tradições. Houve uma grande chegada de pessoas do povo Mende, e hoje muitos afro-americanos vão à África para localizar seus antepassados. O que se vê nesses estudos da família, então, é que estão sendo consideradas 
as pesquisas de historiadores, de genealogistas e de geneticistas. Veja, os historiadores não são desconsiderados. Penso que, para o caso brasileiro, estudos nesse sentido são bem-vindos, de retomada de tradições, e a consciência de que essas tradições são plurais.

Ana Carolina de Carvalho Viotti é também historiógrafa do Centro de Documentação e Apoio à Pesquisa Histórica. Esta entrevista foi realizada no âmbito do projeto temático "Escritos sobre os Novos Mundos: uma história da construção de valores morais em lingua portuguesa", financiado pela FAPESP 


\section{Referências bibliográficas}

KARASCH, Mary C. Amaranth; Angola; Guine, Guinea; Manioc; Mina; slavery: Brazil. In: TENENBAUM, Barbara. Encyclopedia of Latin American History and culture. Nova York: Charles Scribner's, 1996.

. As mulheres livres de Corno Brasil Central, 1779-1832. Revista da Sociedade Brasileira de Pesquisa Histórica, Curitiba, n. 15, p. 3-20, 1998. . A vida dos escravos no Rio de Janeiro, 1808-1850. Tradução de Pedro Maia Soares. São Paulo: Companhia das Letras, 2000. . Bartering books: doing research in Central Brazil. Oakland Journal, n. 2, p. 39-49, outono de 2000.

. Brazil: overview [of Brazilian slavery]. In: MILLER, Joseph (Ed.). Encyclopedia of world slavery. Nova York: Macmillan Reference, 1998. p. 115-134.

. Central Africans in Central Brazil. In: HEYWOOD, Linda M. Central Africans and cultural transformations in the American diaspora. Cambridge: Cambridge University Press, 2002. p. 117-151.

. Concubinato e casamento na capitania de Goiás. Tradução de Angela Domingues. In: SILVA, Maria Beatriz Nizza da. Sexualidade, família e religião na colonização do Brasil. Lisboa: Livros Horizonte, 2001. p. 91-102.

. Conflitos e resistência interetnicos na fronteira brasileira de Goiás, nos anos 1750 a 1890. Revista da Sociedade Brasileira de Pesquisa Histórica, Curitiba, n. 12, p. 31-49, 1997. . Free women of color in Central Brazil, 1779-1832. In: GASPAR, David Barry; HINE, Darlene Clark (Ed.). Beyond bondage: free women of color in the Americas. Urbana: University of Illinois Press, 2004. . História das doenças e dos cuidados médicos na capitania de Goiás [1735-1825]. In: CASTELLO, Lena; FREITAS, Branco F. Saúde e doenças em Goiás. Goiânia: UFG, 1999. p. 19-62. . Índios ladinos, intérpretes e intermediários na capitania de Goiás, 1775-1835. Revista da Sociedade Brasileira de Pesquisa Histórica, Curitiba, n. 19, p. 61-69, 2000.

. Inter-ethnic conflict and survival strategies on the Tocantins-Araguaia frontier, 17501890.In: GUY, Donna J.; SHERIDAN, Thomas E. Contested ground. Tucson: University of Arizona Press, 1998. p. 115-134.

Minha nação: identidades escravas no fim do Brasil colonial. Tradução de Angela Domingues. In: SILVA, Maria Beatriz Nizza da. Brasil: colonização e escravidão. Rio de Janeiro: Nova Fronteira, 1999. p. 127-141.

. Os quilombos do ouro na capitania de Goiás. In: REIS, João José; GOMES, Flavio dos Santos. Liberdade por um fio: história dos quilombos no Brasil. São Paulo: Companhia das Letras, 1996. p. 240-262.

. Rethinking the conquest of Goiás, 1775-1819. The Americas, n. 61, p. 463-492, 2005.

Slave life in Rio de Janeiro. Princeton: Princeton University Press, 1987.

. Slave women on the Brazilian frontier in the nineteenth century, In: GASPAR,

David; HINE, Darlene Clark. More than chattel: black women and slavery in the Americas. Bloomington: Indiana University Press, 1996. p. 79-96.

. The periphery of the periphery? Vila Boa de Goiás, 1780-1835. In: DANIELS, Christine; KENNEDY, Michael V. Negotiated empires: centers and peripheries in the Americas, 15001820. Nova York/Londres: Routledge Press, 2002. p. 143-169.

. Zumbi of Palmares: challenging the Portuguese colonial order. In: ANDRIEN, Kenneth

J. The human tradition in colonial Latin America. Wilmington, DE: Scholarly Resources, 2002. p. 104-120.

; BURNS, E. Bradford; HERNANDEZ, Eduardo (Ed.). Teaching Latin American history. Los Angeles: University of California Press, 1977.

; TENENBAUM, Barbara A. (Org.). The encyclopedia of Latin American history. Nova

York: Charles Scribner's Sons, 1996. 5 v. 